\title{
Vascular Anomalies of the Upper Extremity
}

\author{
Benjamin J. Jacobs, MD, Alex Anzarut, MD, and Joseph E. Imbriglia, MD \\ Department of Orthopaedic Surgery, University of Pittsburgh Medical Center, Pittsburgh, PA; \\ Rebound Orthopedics \& Neurosurgery, Vancouver, WA; Victoria Surgery, BC, Canada
}

\section{Abstract}

The topic of vascular anomalies is uncommon in the hand surgery literature, but hand surgeons do diagnose and treat patients with hemangiomas and vascular malformations. These are separate entities and require different treatment strategies. Proper diagnosis will lead to timely and appropriate treatment.

\section{Keywords}

Arm; hand; hemangioma; malformation; vascular; venous

Hemangiomas occur primarily in children, and most reports are published in the pediatric literature. Hemangioma publications are also common in plastic surgery journals and head and neck literature, as a result of the need for appropriate coverage. There are relatively few publications in the hand surgery literature. Many recent publications emphasize the differences between hemangiomas and vascular malformation. ${ }^{1}$ The primary distinction is that hemangiomas have spontaneous involution, whereas vascular malformations do not.

\section{HEMANGIOMAS}

\section{Epidemiology}

Vascular tumors are common in children and account for approximately $65 \%$ of childhood tumors. ${ }^{2}$ Hemangiomas occur in $7 \%$ to $10 \%$ of infants. ${ }^{3}$ Hemangiomas are benign, and $30 \%$ are present at birth, whereas the remainder are apparent by 4 weeks of age. Hemangiomas have a characteristic phase of rapid growth followed by a static period and then a slow involution. Hemangiomas do not recur.

The growth phase of a hemangioma is a cellular proliferation and not a hypertrophic growth. This growth is accelerated out of proportion to the growth of the child and lasts until approximately one year of age. By this time, the hemangioma is firm, of variable color, and not affected in size or consistency by the positioning of the arm (Fig. 1). The static phase is actually still a growth phase for hemangiomas. The distinction between this phase and the previous growth phase is that the growth in the mass now matches the growth of the child.

Corresponding author: Joseph E. Imbriglia, MD, Hand Fellowship Program, Department of Orthopaedic Surgery, University of Pittsburgh Medical Center, Hand and Upper Ex Center, 6001 Stonewood Drive, Wexford, PA 15090; jimbriglia@ handupperex.com. No benefits in any form have been received or will be received related directly or indirectly to the subject of this article. 
In addition, there can be color changes in the mass during this phase. This phase can last for years. The involution of the hemangioma is typically a slow process of softening, shrinkage, and color change. The mass might not appear as normal skin after involution.

Telangiectasias, fibrous masses, and inelastic skin commonly remain. ${ }^{4}$ Approximately $50 \%$ of hemangiomas involute by 5 years of age and $70 \%$ by 7 years. ${ }^{5}$ Hemangiomas affect the upper extremity in $15 \%$ of cases. ${ }^{6}$ Infantile hemangiomas do not alter the growth of the affected limb and rarely cause functional problems. ${ }^{4,6}$ This is true regardless of the size of the lesion. An additional concern, the presence of multiple cutaneous hemangiomas, should prompt referral for evaluation of visceral hemangiomas. ${ }^{5}$

\section{Other types of hemangiomas}

Congenital hemangiomas that appear fully formed at birth are much less common. These hemangiomas typically involute rapidly and are called rapidly involuting congenital hemangiomas. Occasionally, they remain stable long term and are called noninvoluting congenital hemangiomas. Although these congenital hemangiomas differ from more typical infantile hemangiomas in their presentation, they do share histologic features with infantile hemangiomas and can easily be confused. ${ }^{3,5}$ Magnetic resonance imaging (MRI) findings can be helpful in cases in which the hemangioma does not follow a typical course. Ultimately, biopsy or excision can be diagnostic. ${ }^{5}$

Another different clinical entity from the typical infantile hemangioma is the intramuscular hemangioma. Intramuscular hemangiomas are uncommon and are estimated at less than $1 \%$ of hemangiomas. Intramuscular hemangiomas are more prevalent in the lower extremity than in the upper extremity. Growth and involution of intramuscular hemangiomas might follow a time course similar to infantile hemangiomas, but this point is debated. ${ }^{7}$ These masses can persist and present in adolescence as a painful swelling, particularly during periods of strenuous exercise. Diagnostic imaging might prove to be particularly useful in the diagnosis of intramuscular hemangioma, especially if surgical intervention is planned. ${ }^{8,9}$ In one review of 6 children with intramuscular hemangiomas, MRI was helpful and showed the lesions with the same or slightly higher signal compared to muscle on $\mathrm{T} 1$ and some abnormal signal on T2. Gadolinium was useful in differentiating these lesions because the mass enhances. All of the patients in this study had surgery with uniform, symptomatic relief following excision. Indications for excision were pain secondary to the mass, suspicion of malignancy with rapid tumor growth, thrombocytopenia, and cosmetic concerns. The authors concluded that the diagnosis of intramuscular hemangiomas is difficult compared to that of superficial hemangiomas and that MRI was useful for diagnosis and surgical planning. ${ }^{7}$

\section{EDUCATIONAL OBJECTIVES}

- Describe the histology of hemangiomas.

- Discuss the natural history of hemangiomas.

- List the genetic factors associated with hemangioma development.

- State the various types of vascular malformations. 
- Compare and contrast the various types of high-flow vascular malformations.

- Discuss the treatment options for vascular malformations.

Earn up to 2 hours of CME credit per JHS issue when you read the related articles and take the online test. To pay the $\$ 20$ fee and take this month's test, visit http:// www.assh.org/professionals/jhs.

Histology

Histologic evaluation of hemangiomas reveals 2 distinct types. Capillary type lesions are nonvascular, with a spongy appearance. The cavernous type has large vessels, with thin walls lined by flat endothelium. The distinction, however, is difficult because there is a spectrum of disease. ${ }^{7,10}$ Histologic evaluation of intramuscular hemangiomas is important because these lesions can be confused with rhabdomyosarcoma, synovial sarcoma, Ewing's sarcoma, neuroblastoma, and angiosarcoma. ${ }^{7,10}$

During the proliferating phase, the histologic appearance demonstrates rapid turnover of the endothelium with enlarging vessel diameter. There are large endothelial cells lining the capillary lumens. As the hemangioma matures and enters the static growth phase, there is flattening of the endothelial cells. During the involution phase, there is considerable mast cell infiltration and progressive fibrosis of the mass. Mast cells might be required for involution of the hemangioma. 5,11

\section{Etiology}

The etiology of hemangiomas is unknown. Recent advances in genetics have indicated that genes necessary for normal development might malfunction to cause hemangiomas. An association has been found between hemangioma development and the pattern of Notch gene expression in hemangioma cells. Notch signaling has a role in the stabilization of arterial endothelial fate and angiogenesis. Notch expression changes as cells progress from hemangioma-derived stem cells into hemangioma endothelial cells and then changes again as the hemangioma involutes. ${ }^{12}$ Abnormal production of vascular endothelial growth factor might also lead to hemangioma formation. ${ }^{5}$ There is a female predominance of hemangiomas between 3:1 and 5:1, and increased estrogen levels have been documented in children with hemangiomas, suggesting a hormonal influence. ${ }^{13} \mathrm{~A}$ connection with estrogen is further evident because estrogen levels decrease after hemangioma treatment. ${ }^{14}$ Understanding the genetics behind hemangioma development helps differentiate hemangiomas from other vascular anomalies. Unlike vascular malformations and other vascular tumors, hemangiomas uniquely express GLUT-1, an erythrocyte-type glucose transporter protein. ${ }^{15}$ In the future, this expression might provide therapeutic targets for treating hemangiomas.

\section{Imaging}

There is rarely any abnormality within the adjacent bones in patients with hemangiomas. Thus, conventional radiographs are of limited value. In a report of 89 patients with mixed diagnoses, some of which were hemangiomas, 20 of the 89 patients had normal radiographs, 
making them unreliable. Furthermore, in this same study, 21 patients had computed tomography scans of their lesions, and only 4 of these scans were diagnostic for their mass. ${ }^{1}$

Magnetic resonance imaging is a common imaging modality obtained in patients with hemangiomas. In an infant, however, anesthesia is required, and advanced imaging is unnecessary if the diagnosis is readily apparent. ${ }^{16}$ On MRI, hemangiomas appear as wellcircumscribed lesions that enhance with gadolinium. The T1 signal is typically low or isointense to muscle, and the T2 signal is high, with some heterogeneity. The heterogeneity corresponds to the feeding and draining vessels that are higher flow areas. ${ }^{17}$

Ultrasound is also used for diagnosis of hemangiomas when the diagnosis is questionable. The greatest value of ultrasound is to delineate the extent of a deep lesion, particularly if surgical intervention is planned. ${ }^{17}$ Angiography demonstrates a mass with wellcircumscribed margins and a blush. Angiography is usually unnecessary because MRI and magnetic resonance angiography provide adequate information. Angiography might be useful when considering embolization of the mass.

\section{Treatment principles}

Treatment of hemangiomas is primarily observation. Most hemangiomas will spontaneously involute. However, some symptomatic or persistent lesions require additional management. Treatment options include intralesional or systemic steroids, which have reportedly mixed success. Oral steroids might have success in halting lesion growth, although the systemic effects must be considered. There are also reports of using pulsed dye lasers, particularly in ulcerated hemangiomas, resulting in decreased pain and reduced healing time. ${ }^{18,19}$ Sclerosing agents and bleomycin have been used with equivocal results. ${ }^{5,20}$ Intralesional bleomycin injections have shown success in treating infantile hemangiomas; however, multiple rounds are necessary, and bleomycin can cause local pigmentation changes, scarring, and, in large doses, can result in pulmonary fibrosis. ${ }^{21}$ Additional treatment might be required when the hemangioma is refractory to first-line measures, has a mass effect that is harming adjacent structures, or is causing hematological or hemodynamic instability. In Kasabach-Merritt syndrome, hemangiomas can cause platelet trapping and, ultimately, thrombocytopenia. This scenario is particularly problematic if the hemangioma has ulcerated and bleeds. Ulceration occurs in approximately $30 \%$ of hemangiomas, typically during the proliferative phase, and most often, local measures are sufficient to control the lesion. In refractory cases, lasers have demonstrated good success. ${ }^{5,22}$

Surgical reviews of hemangioma are limited. In a retrospective review of 89 patients treated over 25 years, Tang et al. ${ }^{1}$ evaluated a variety of vascular tumors, including hemangiomas. This study showed a marked decrease in recurrence following removal with clean surgical margins. Intralesional or marginal resection resulted in a 19\% recurrence rate. Larger tumor size was the primary determinant for recurrence. Overall, $83 \%$ of the patients reported excellent function with no impairment, and only $2 \%$ reported poor function. ${ }^{1}$ 


\section{VASCULAR MALFORMATIONS}

Vascular malformations are a greater treatment dilemma for the hand surgeon when compared with hemangiomas. These masses are often present at birth, but go unnoticed until later in life. Vascular malformations are caused by errors of vascular tree morphogenesis. ${ }^{2,11}$ They do not have involution and grow in proportion to the individual, although their growth might accelerate during puberty and pregnancy. ${ }^{23}$ Male and female patients have equal incidence.

\section{Classification}

Vascular malformations primarily fall into 2 categories: high-flow and low-flow vascular malformations. Low-flow lesions are much more common than high-flow lesions (7:1 ratio). ${ }^{2}$ Low-flow lesions are typically soft and compressible. Low-flow vascular malformations are divided into capillary, venous, lymphatic, and combined types. This distinction is made based on the predominant type of vessel comprising the mass. High-flow lesions are typically arterial-venous (AV) malformations.

\section{Imaging of vascular malformations}

Conventional radiographs often demonstrate phleboliths within the mass. Also, in contrast to hemangiomas, there can be associated skeletal hypertrophy or bony destruction. Magnetic resonance imaging with contrast is helpful to delineate the extent of the malformation and can replace an angiogram. In one recent study, MRI was found to be particularly useful because clinicians underestimated the size of the mass on physical examination in $76 \%$ of patients. ${ }^{24}$ Ultrasound can determine the size of the lesion and demonstrate channels and cysts, which can characterize the flow within the lesion. Angiography allows the anatomy to be clearly visualized, except in the case of lymphatic malformation.

\section{Histology of vascular malformations}

Histologic analysis of vascular malformations reveals that the endothelium is essentially normal in appearance, and there is no increase in mast cell populations. This is in contrast to hemangiomas. The predominant type of vessel composing the mass is readily visible.

\section{General treatment principles}

Treatment for vascular malformations falls into several categories. Conservative measures are often the first step in treatment and consist of aspirin, elevation, and compressive dressings. ${ }^{25}$ Their efficacy is marginal, and additional treatment is often necessary. Sclerotherapy has gained popularity because it has relatively good success in controlling the lesions in most cases and improving the lesions in almost all cases. ${ }^{26,27}$ Sclerotherapy before surgery can also be used to decrease blood loss. ${ }^{25}$ Using lasers to treat vascular malformations is an attractive idea, and the technique continues to evolve. Buckmiller ${ }^{25}$ reported that using lasers placed deep to the skin with ultrasound guidance has been helpful. Surgery for vascular malformation remains the only way to completely extricate the abnormal tissue. ${ }^{25}$ Surgery can be difficult, however, owing to the abnormal anatomy as well as the potential for substantial bleeding. Before any substantial surgical resection, a coagulation profile should be obtained to assess for any underlying coagulopathy. ${ }^{28}$ 
Dayicioglu et al. ${ }^{6}$ recently reported on a series of vascular anomalies in the upper extremity, along with their surgical treatment, and detailed some remarkable results.

\section{Low-flow venous malformations}

The most common low-flow malformation is the venous malformation. These malformations often engorge when dependent and collapse when elevated. They can go unnoticed until some unrelated trauma and can present as pain, swelling, or decreased function. Pain can be effort-dependent or can occur in the morning upon waking. The skin might be slightly blue. ${ }^{16}$ There is hormonal control over the growth of venous malformations because, during pregnancy or with oral contraceptives, the lesion can grow rapidly. ${ }^{24}$ Conservative measures are the mainstays of management. Surgery might be necessary in painful lesions, for cosmetic concerns, or if the mass has encroached on surrounding structures. Adjunctive measures such as sclerotherapy can be used. ${ }^{25}$ Surgery should be carefully planned because complications are frequent (Fig. 2). ${ }^{28,29}$

The diagnosis can be aided by ultrasound because the mass will be hypoechoic, serpiginous, and compressible. There will be a venous monophasic flow. If there is an absence of signal within the lesion, thrombosis might be the cause. Magnetic resonance imaging can be helpful in determining the extent of the lesion. Venous malformations have an isointense signal on T1 images and enhance on T2 imaging. Venous malformations can involve both deep and superficial locations and can invade bone, muscle, joints, and nerves. Magnetic resonance angiography of the hand might further outline the mass. Angiography itself is not particularly helpful in evaluating venous malformations because the mass is only partially opacified during the venous phase. ${ }^{16,24}$

Treatment outcomes of intramuscular venous malformations are generally acceptable. Hein et al. ${ }^{30}$ reviewed 176 patients and demonstrated patient improvement in $66 \%$ who had surgery alone and in $92 \%$ of patients who had both sclerotherapy and surgery. There are other scattered reports of vascular masses requiring surgery, and the short- and intermediateterm outcomes for resection of these masses are good. Conservative measures, however, should be the mainstay of treatment. ${ }^{28}$

\section{Low-flow capillary malformations}

Capillary low-flow vascular malformations are also known as port wine stains and nevus flammeus. These superficial lesions can be associated with a deep component that can be partially lymphatic in nature. They typically appear in infants as pink macules or patches and follow a mixed course. Some of these lesions fade with time, whereas others become darker and thicker and might develop hyperkeratoses. They can also be associated with bone and soft tissue hypertrophy (Fig. 3). ${ }^{28}$

Histologically, capillary malformations have a large number of ectatic dermal blood vessels. These vessels can become larger and denser with age. Imaging of capillary malformations is not helpful in making a clinical diagnosis. Treatment is usually with lasers, although topical imiquimod is another option. ${ }^{31}$ Several studies have demonstrated good success in lightening the lesions using lasers. Younger patients seem to respond better to laser 
treatment than do older patients, possibly because the lesion is less dense and has smaller vessels. $^{28}$

\section{Low-flow lymphatic malformations}

Lymphatic low-flow vascular malformations, previously called cystic hygromas or lymphangiomas, result in accumulation of fluid in the limb from poor lymph flow. The resultant limb enlargement is not growth but swelling. Presentation of these masses can be quite similar to venous malformations with a compressible mass that can be painful. ${ }^{16}$ Ultrasound can be useful in distinguishing a venous from a lymphatic malformation. Lymphatic malformations have many large anechoic fluid-filled areas with septae. These masses are avascular. ${ }^{16}$ Magnetic resonance imaging is useful in evaluating lymphatic malformations; $\mathrm{T} 1$ images are low in signal, and T2 images will show a high signal. Gadolinium contrast can add additional detail, with enhanced walls and septae contrasting with venous malformations that enhance within the blood-filled area. ${ }^{16,25}$ Treatment is conservative, with external compression as the mainstay of treatment. Often, the lesion becomes less prominent as the child grows. ${ }^{32}$ Surgery or sclerotherapy can be considered for distinct, macrocystic lesions. ${ }^{29,32}$ In fact, the results of sclerotherapy for lymphatic malformation seem promising. The outcome is variable, with results depending on the type of sclerosing agent and the size of the mass. Larger macrocystic masses $(>2 \mathrm{~cm})$ respond better to treatment than do microcystic masses $(<2 \mathrm{~cm}){ }^{25}$ Surgery or surgery with sclerotherapy might be the only options for treatment of lymphatic malformations that are uncontrolled with conservative measures because lasers are not helpful. ${ }^{22}$ Large lymphatic malformations can result in substantial swelling and deformity, with considerable patient morbidity. 25,33

\section{High-flow vascular malformation}

High-flow vascular malformations are typically abnormal AV anastomoses. High-flow vascular malformations often present at an early age and are not responsive to elevation compared with low-flow malformations. Symptoms can include increased warmth, redness, extremity pain, palpable thrills, and ischemia distal to the lesion. Ultrasound can be used to help diagnose an AV malformation. Pulsatile blood flow suggests that there is a considerable arterial component to the mass. In addition, measurements of flow rates can add to the diagnostic accuracy because increased velocity of blood flow within the mass suggests arterialization. ${ }^{16}$ Magnetic resonance imaging of high-flow malformations will commonly have a low signal on both $\mathrm{T} 1$ and $\mathrm{T} 2$, corresponding to the high-flow arteries and arterialized veins. ${ }^{16,25}$ Khong et al. ${ }^{34}$ studied high-flow vascular malformations to assess MRI's ability to differentiate these from low-flow lesions. They found that MRI can often be inconclusive. Angiography has been vital in imaging AV malformations and allows for concurrent treatment with embolization. ${ }^{25}$ Angiography demonstrates the AV shunts, as well as large feeding arteries and venous outflow. ${ }^{16}$ Treatment typically includes compressive dressings, embolization, surgical resection, or even amputation. ${ }^{16}$ Carefully planned embolization done in stages can be quite successful in treating extremity AV malformations. Rockman et al. ${ }^{35}$ found that $92 \%$ of patients had no symptoms or improved symptoms for an average of 56 months, with staged embolization. Embolization before surgery might be helpful to minimize blood loss. Surgery should be performed within 2 days of embolization 
because collateral blood flow can develop quickly. ${ }^{25,36}$ Determining the extent of resection at the time of surgery is challenging due to the possible complications of bleeding and vascular compromise of distal tissues. Incomplete resection can lead to recurrence. ${ }^{25}$

\section{ASSOCIATED SYNDROMES}

Klippel-Trenauney syndrome consists of a mixed venous and lymphatic lesion, cutaneous nevus flammeus, varicosities, and hypertrophy of bone and nearby soft tissues in one or more extremities. Kasabach-Merritt syndrome is a bleeding diathesis due to a consumptive coagulopathy with thrombocytopenia and purpura secondary to a vascular lesion. Maffucci's syndrome is a rare, congenital enchondromatosis and hemangiomatosis that appears at birth. It results in deformities of the hands and can have malignant transformation. Parkes-Weber syndrome includes AV fistulas, vein varicosities, and limb hypertrophy from lipomatosis and lymphatic hyperplasia. Patients can have high-flow lesions leading to symptoms as severe as heart failure.

Hemangiomas and vascular malformations are distinctly different and require different treatment algorithms. Hemangiomas are common in newborns and have a characteristic phase of rapid growth, followed by a static period, and then a slow involution.

Hemangiomas do not recur. In contrast, vascular tumors present later and do not have spontaneous involution. The treatment depends on the size of the lesion and the predominant vessel type. Low-flow vascular malformations are more common than high-flow lesions. Imaging can help distinguish the type and extent of the lesion. Treatment options include embolization and/or surgical excision. Recurrence is common following incomplete resection.

\section{References}

1. Tang P, Hornicek FJ, Gebhardt MC, Cates J, Mankin HJ. Surgical treatment of hemangiomas of soft tissue. Clin Orthop Relat Res. 2002; 399:205-210. [PubMed: 12011711]

2. Fleming AN, Smith PJ. Vascular cell tumors of the hand in children. Hand Clin. 2000; 16:609-624. [PubMed: 11117051]

3. Blei F. Basic science and clinical aspects of vascular anomalies. Curr Opin Pediatr. 2005; 17:501509. [PubMed: 16012263]

4. Enjolras O, Chapot R, Merland JJ. Vascular anomalies and the growth of limbs: a review. J Pediatr Orthop B. 2004; 13:349-357. [PubMed: 15599224]

5. Smolinski KN, Yan AC. Hemangiomas of infancy: clinical and biological characteristics. Clin Pediatr (Phila). 2005; 44:747-766. [PubMed: 16327961]

6. Dayicioglu D, Martell EG, Ogilvie M, Gozu A, Panthaki ZJ, Armstrong MB. Vascular anomalies of the upper extremity in children. J Craniofac Surg. 2009; 20:1025-1029. [PubMed: 19568187]

7. Muramatsu K, Ihara K, Tani Y, Chagawa K, Taguchi T. Intramuscular hemangioma of the upper extremity in infants and children. J Pediatr Orthop. 2008; 28:387-390. [PubMed: 18362809]

8. Ranero-Juarez AG, Rosales-Galindo VM, Leon-Takahashi AM, Arenas-Guzman R, Garcia C. Intramuscular hemangiomas of the extremities: report of six cases. Int J Dermatol. 2009; 48:875878. [PubMed: 19659867]

9. Wisniewski SJ, Newcomer K, Stanson AW. Intramuscular hemangioma of the foot: a diagnostic dilemma. Med Sci Sports Exerc. 2005; 37:1655-1657. [PubMed: 16260963]

10. Wild AT, Raab P, Krauspe R. Hemangioma of skeletal muscle. Arch Orthop Trauma Surg. 2000; 120:139-143. [PubMed: 10738870] 
11. Tille JC, Pepper MS. Hereditary vascular anomalies: new insights into their pathogenesis. Arterioscler Thromb Vasc Biol. 2004; 24:1578-1590. [PubMed: 15231518]

12. Wu JK, Adepoju O, De Silva D, Baribault K, Boscolo E, Bischoff J, et al. A switch in Notch gene expression parallels stem cell to endothelial transition in infantile hemangioma. Angiogenesis. 2010; 13:15-23. Epub 2010 Jan 13. [PubMed: 20069356]

13. Mulliken JB, Fishman SJ, Burrows PE. Vascular anomalies. Curr Probl Surg. 2000; 37:517-584. [PubMed: 10955029]

14. Sun ZY, Yang L, Yi CG, Zhao H, Han DL, Yang T, et al. Possibilities and potential roles of estrogen in the pathogenesis of proliferation hemangiomas formation. Med Hypotheses. 2008; 71:286-292. [PubMed: 18434035]

15. North PE, Waner M, Mizeracki A, Mihm MC Jr. GLUT1: a newly discovered immunohistochemical marker for juvenile hemangiomas. Hum Pathol. 2000; 31:11-22. [PubMed: 10665907]

16. Drape JL, Feydy A, Guerini H, Desmarais E, Godefroy D, Le Viet D, et al. Vascular lesions of the hand. Eur J Radiol. 2005; 56:331-343. [PubMed: 16298677]

17. Gampper TJ, Morgan RF. Vascular anomalies: hemangiomas. Plast Reconstr Surg. 2002; 110:572585. quiz 586; discussion 587-588. [PubMed: 12142679]

18. David LR, Malek MM, Argenta LC. Efficacy of pulse dye laser therapy for the treatment of ulcerated haemangiomas: a review of 78 patients. Br J Plast Surg. 2003; 56:317-327. [PubMed: 12873458]

19. Kim HJ, Colombo M, Frieden IJ. Ulcerated hemangiomas: clinical characteristics and response to therapy. J Am Acad Dermatol. 2001; 44:962-972. [PubMed: 11369908]

20. Matsumoto K, Nakanishi H, Koizumi Y, Seike T, Kanda I, Kubo Y. Sclerotherapy of hemangioma with late involution. Dermatol Surg. 2003; 29:668-671. discussion 671. [PubMed: 12786717]

21. Pienaar C, Graham R, Geldenhuys S, Hudson DA. Intralesional bleomycin for the treatment of hemangiomas. Plast Reconstr Surg. 2006; 117:221-226. [PubMed: 16404271]

22. Astner S, Anderson RR. Treating vascular lesions. Dermatol Ther. 2005; 18:267-281. [PubMed: 16229727]

23. Upton J, Coombs C. Vascular tumors in children. Hand Clin. 1995; 11:307-337. [PubMed: 7635889]

24. Rinker B, Karp NS, Margiotta M, Blei F, Rosen R, Rofsky NM. The role of magnetic resonance imaging in the management of vascular malformations of the trunk and extremities. Plast Reconstr Surg. 2003; 112:504-510. [PubMed: 12900608]

25. Buckmiller LM. Update on hemangiomas and vascular malformations. Curr Opin Otolaryngol Head Neck Surg. 2004; 12:476-487. [PubMed: 15548904]

26. Berenguer B, Burrows PE, Zurakowski D, Mulliken JB. Sclerotherapy of craniofacial venous malformations: complications and results. Plast Reconstr Surg. 1999; 104:1-11. discussion 2-5. [PubMed: 10597669]

27. Pappas DC Jr, Persky MS, Berenstein A. Evaluation and treatment of head and neck venous vascular malformations. Ear Nose Throat J. 1998; 77:914-916. 918-922. [PubMed: 9846469]

28. Garzon MC, Huang JT, Enjolras O, Frieden IJ. Vascular malformations: part I. J Am Acad Dermatol. 2007; 56:353-370. quiz 371-374. [PubMed: 17317485]

29. McClinton MA. Tumors and aneurysms of the upper extremity. Hand Clin. 1993; 9:151-169. [PubMed: 8383136]

30. Hein KD, Mulliken JB, Kozakewich HP, Upton J, Burrows PE. Venous malformations of skeletal muscle. Plast Reconstr Surg. 2002; 110:1625-1635. [PubMed: 12447041]

31. Kouba DJ, Yip D, Fincher EF, Moy RL. Topical imiquimod in the treatment of a long-standing capillary malformation. Br J Dermatol. 2007; 157:1071-1072. [PubMed: 17854371]

32. Higuera S, Gordley K, Metry DW, Stal S. Management of hemangiomas and pediatric vascular malformations. J Craniofac Surg. 2006; 17:783-789. [PubMed: 16877935]

33. Al-Qattan MM, Murray KA, El-Shayeb A. Arteriovenous vascular malformations confined to the hand: an algorithm of management based on a new classification. J Hand Surg. 2006; 31B:266273. 
34. Khong PL, Burrows PE, Kozakewich HP, Mulliken JB. Fast-flow lingual vascular anomalies in the young patient: is imaging diagnostic? Pediatr Radiol. 2003; 33:118-122. [PubMed: 12557068]

35. Rockman CB, Rosen RJ, Jacobowitz GR, Weiswasser J, Hofstee DJ, Fioole B, et al. Transcatheter embolization of extremity vascular malformations: the long-term success of multiple interventions. Ann Vasc Surg. 2003; 17:417-423. [PubMed: 14670021]

36. Kademani D, Costello BJ, Ditty D, Quinn P. An alternative approach to maxillofacial arteriovenous malformations with transosseous direct puncture embolization. Oral Surg Oral Med Oral Pathol Oral Radiol Endod. 2004; 97:701-706. [PubMed: 15184851] 


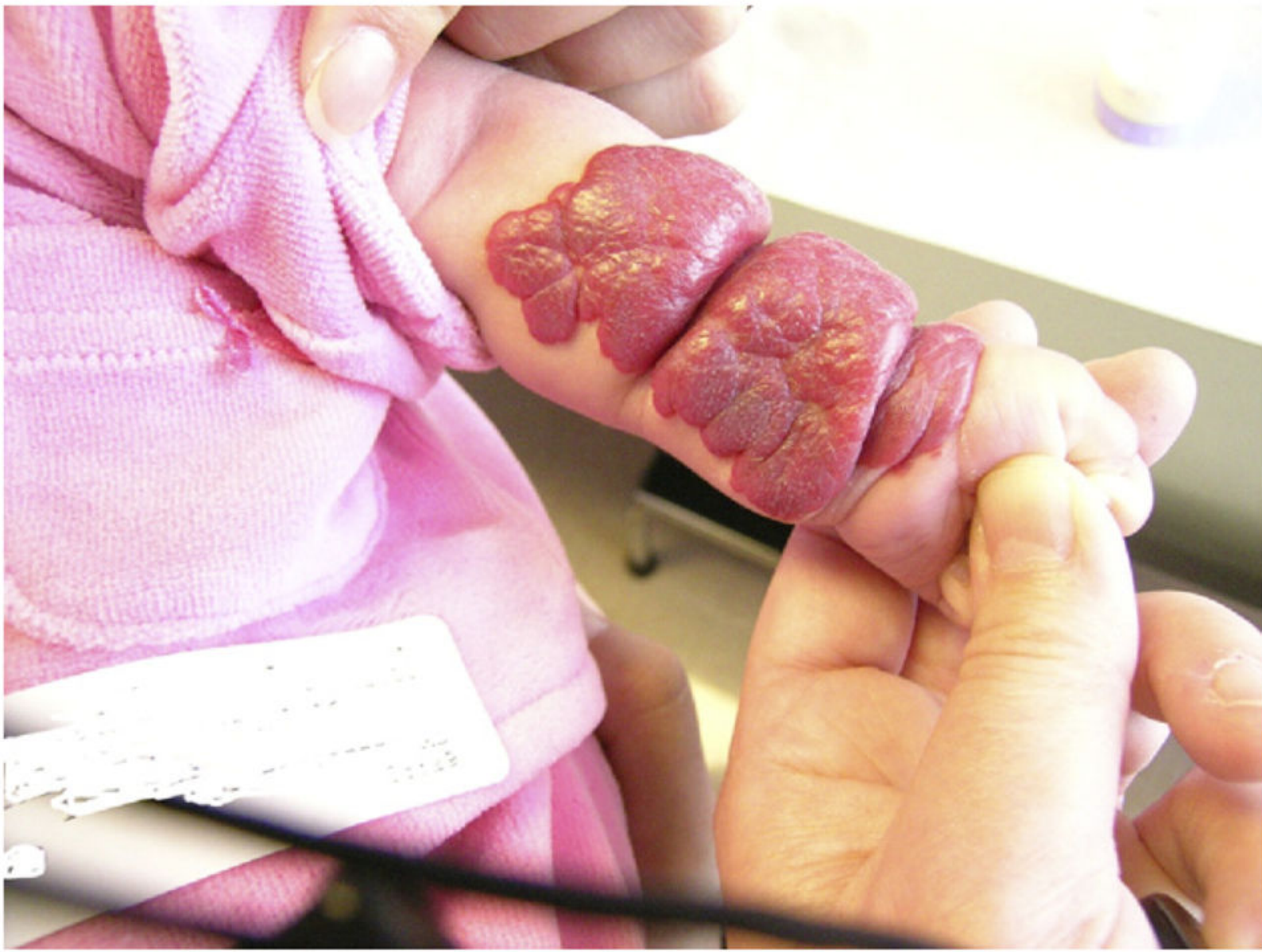

FIGURE 1.

An infant with a hemangioma involving the majority of the upper extremity and hand. The skin is raised, firm, and bosselated, with a vivid crimson color. 


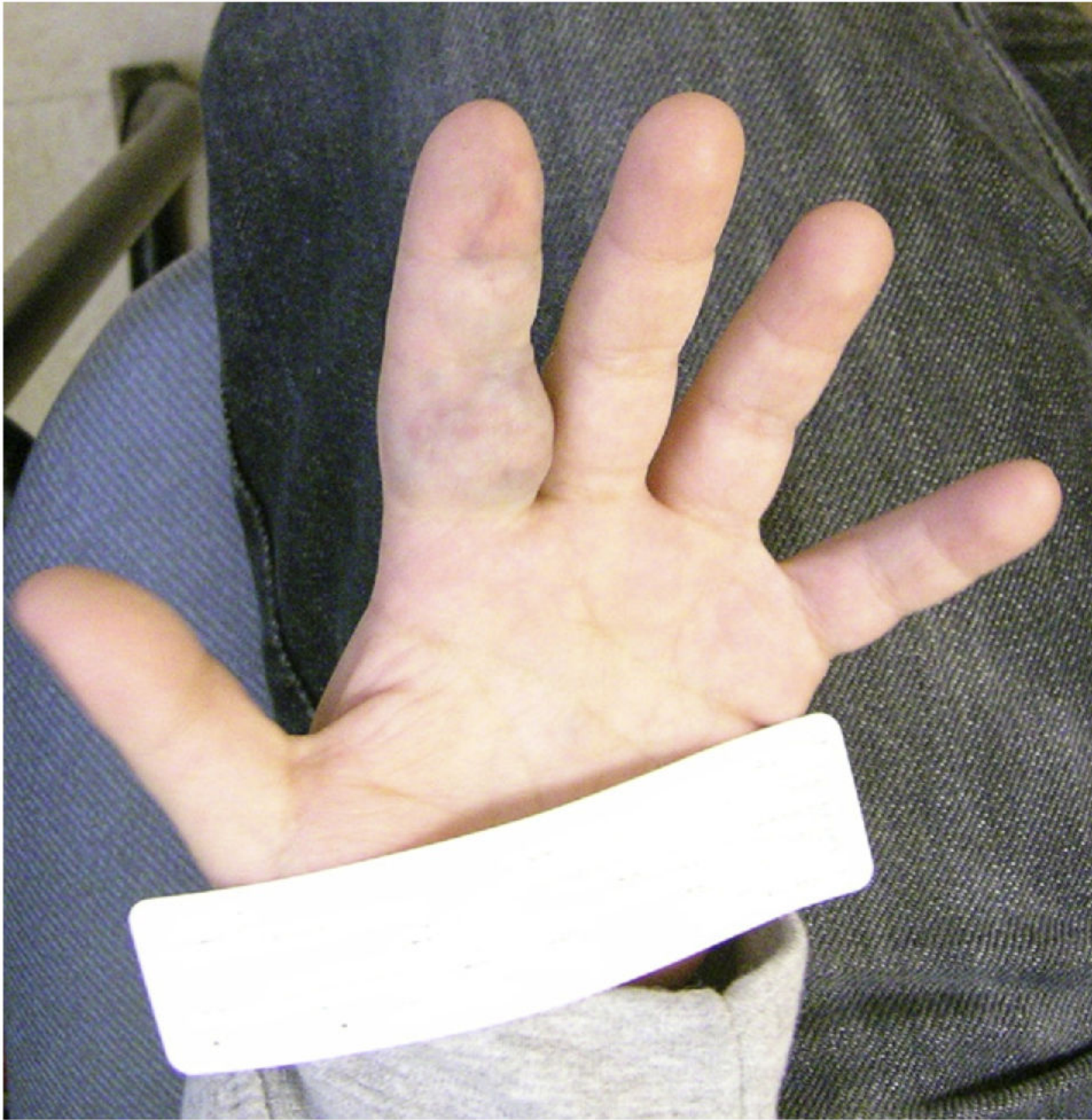

FIGURE 2.

A venous malformation of the finger that is engorged while the patient holds it dependent.

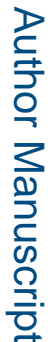




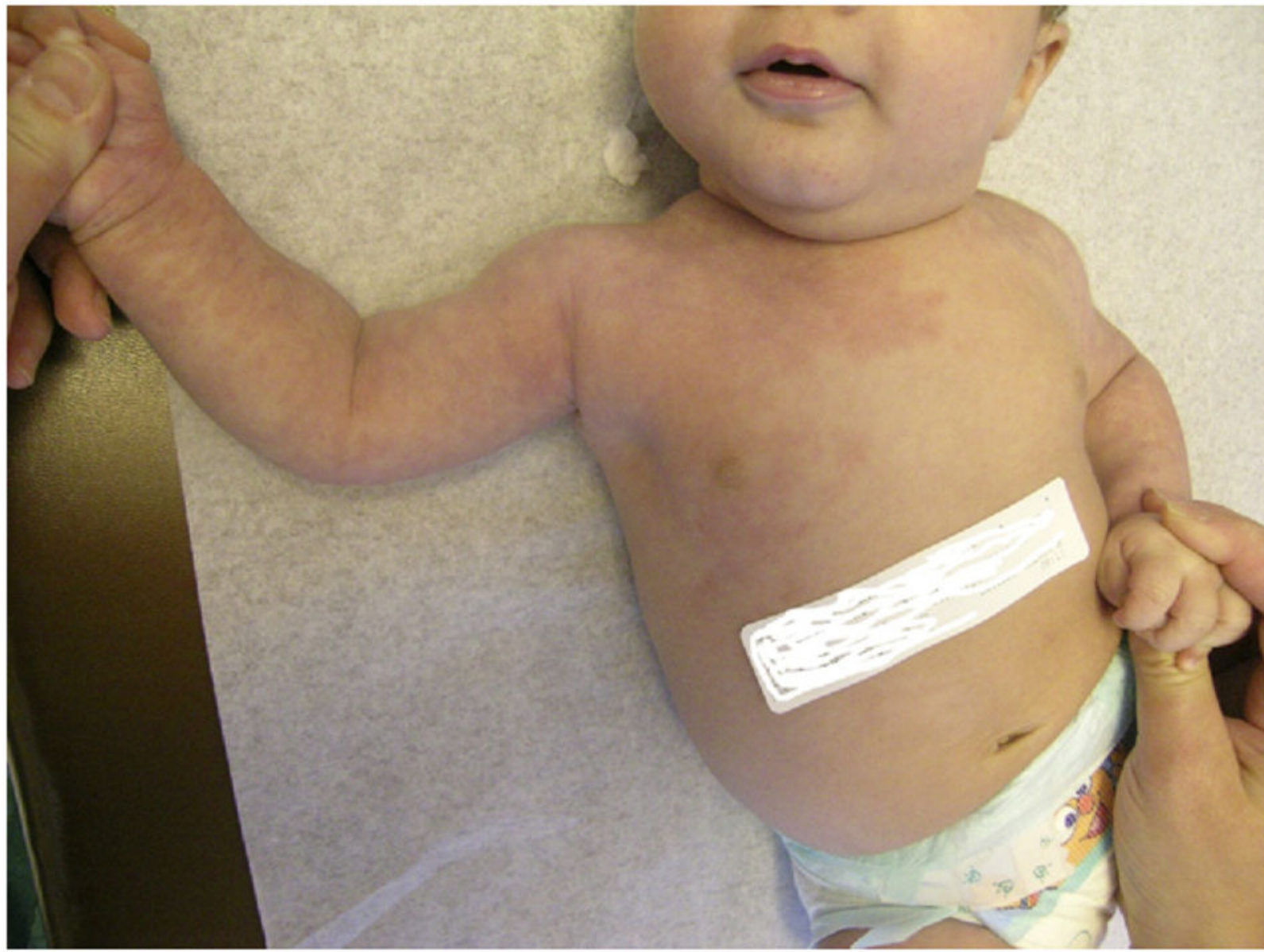

FIGURE 3.

An infant with a vascular malformation involving the entire upper extremity and into the chest wall that was ultimately diagnosed as a capillary malformation. 